\title{
The impact of Ramadan fasting on immune system function during COVID-19 pandemic
}

\author{
Halgord Ali M Farag', Hardi Rafat Baqi², Kawa Khwarahm Hamafarj ${ }^{1}$, Abdel Hamid El Bilbeisi ${ }^{3 *}$, Syamand Ahmed Qadir ${ }^{2}$, Rafee Habib \\ Askandar ${ }^{1}$, Mahmoud Taleb $^{4}$, Amany El Afifi', Manal J. Bakry ${ }^{3}$ \\ ${ }^{1}$ Nursing Department, Technical College of Health, Research Center, Sulaimani Polytechnic University, Sulaimani, Iraq \\ ${ }^{2}$ Medical Laboratory Science, Technical College of Applied Sciences, Research Center, Sulaimani Polytechnic University, Sulaimani, Iraq \\ ${ }^{3}$ Department of Clinical Nutrition, Faculty of Pharmacy, Al Azhar University of Gaza, Gaza Strip, Palestine \\ ${ }^{4}$ Faculty of Pharmacy, Al Azhar University of Gaza, Gaza Strip, Palestine
}

\begin{abstract}
Recently, the infection transmitted by the latest coronavirus (COVID-19), was associated with significant increase in morbidity and mortality, reflecting major public health issue. However, Ramadan fasting throughout an outbreak may be a new phenomenon for many of Muslims worldwide. The aim of this review was to determine the impact of Ramadan fasting on immune system function during COVID-19 pandemic. This review gathered the contemporary information throughout PubMed, Scopus, and Science Direct databases from relevant articles, to provide understanding of the potential impact of Ramadan fasting on the immune system during pandemic viral infection. The results of this review show many justifiable concerns arise to the consequences of refraining the body from essential nutrients and fluids for prolonged periods of time through a day. Especially this practice might intricate the health status of selected groups including the elderly and people having chronic diseases. On the other hand, many studies suggest that intermittent fasting boost the immune response of the body towards infections. Furthermore, there is no conclusive evidence regarding the relationship between fasting and increasing or decreasing the risk of catching a virus or improving oxidative stress status as well. Therefore, Muslims who practice fasting during pandemic face a circumstance in which no concrete scientific evidence proves the safety or danger of this religious practice. We conclude that there are proven benefits of fasting in augmenting the immune response; however, this summoned by many factors including general health status of the person who fasts, lifestyle, and epidemiological circumstances.
\end{abstract}

\begin{abstract}
Abbreviations: COVID-19: Coronavirus; WHO: World health organization; DIT: Developmental immunotoxicology; EPA: Eicosapentaenoic acid; DHA: Docosahexaenoic acid; ACE 2: Angiotensin converting enzyme-2; HCoV-NL63: Human coronavirus NL63; AF: Allele frequencies; AIDS: Acquired immunodeficiency syndrome; COPD: Chronic obstructive pulmonary disease; TBARS: Thiobarbituric acid reactive substances; SOD: Superoxide dismutase; MDA: Malondialdehyde.
\end{abstract}

\section{Introduction}

Recently, the infection transmitted by the latest SARS-COV-2, recognized as coronavirus disease 2019 (COVID-19), was already associated with significant increase in mortality and morbidity, reflecting major public health issue [1]. This year adult healthy Muslims are dealing with new experimentation: the COVID-19 pandemic. Fasting throughout an outbreak may be a new phenomenon for many of us. Fasting is an obligation that not only nourishes the inner self and the closeness to God, but it also improves the safety of the body. Gaining weight and obesity contributed to the risk of adipose tissue and increase the creation of inflammatory factor [2]. However, behavioral changes and its improvement accompanying fasting can be beneficial in lowering body fat and risk of inflammation. Several findings have already shown the implications of Muslim fasting on physiology and disease pathology [3]. Researches have shown that fasting during the holy month of Ramadan is successful in modification of triglyceride and overall HDL- cholesterol [4]. The impact of fasting on the regulation the activity of immune system is another concern considered by researchers. Conflicting finding have been published for diverse immune modulatory signs in healthy and unhealthy volunteers observing the Holy month of Ramadan [5]. However, fasting has been proposed to modulate the immune system significantly. Since these restricting the overall consumption of nutrients could affectively weaken the immune system [6] and associated with biochemical changes [7]. In other hand, fasting cycle, significantly improve persons immune system which is damaged bay aging and chemotherapy [8]. Generally, calorie consumption during Ramadan is lower than at other period of the years, evidence suggest that this decline of daily calorie intake and deprivation significantly strengthens the immune system $[8,9]$. The result of antibody assessment from 35 healthy volunteers during Ramadan fasts, evaluated that the amount of lymphocyte decreased and the concentration of IgG and IgA declined after Ramadan fast compared before Ramadan, but it did not slip below the normal range [10]. Further analysis shows that concentration of IL- 6 and TNF- $\alpha$ and inflammations decreased dramatically during the Ramadan fast related to the non-fast period [11]. Accordingly, the finding of the analysis revealed that a healthier lifestyle improve the synaptic activity of the

${ }^{\star}$ Correspondence to: Abdel Hamid El Bilbeisi, Department of Clinical Nutrition, Faculty of Pharmacy, Al Azhar University of Gaza, Gaza Strip, Palestine, Tel: 0098 (0) 21 88955975; Fax: 0098 (0) 2188955975,E-mail: abed_az@hotmail.com

Key words: coronavirus, immune system, oxidative stress, pandemic, Ramadan fasting

Received: June 12, 2020; Accepted: June 26, 2020; Published: June 30, 2020 
immune system. Considering that refusing food while fasting change the eating behavior and that fasting affects the everyday behaviors of an individual, it appear that modifying the eating pattern and lifestyle will be accompanied by fasting. It induces physiological changes in the body and modulates the immune system as well. In addition fasting can be used to reduce the likelihood of inflammations and increasing the cellular activity of the immune system. With the present the health risk of COVID-19 and the precautions taken by world health organization (WHO), there is continuing scientific discussion that adult Muslims should fast or not. In addition, there is not enough evidence prove that fasting Ramadan negatively impact on immune system or visversa during outbreak of COVID-19 among the Muslim populations. Therefore, the aim of this study was to fill the previous research gap and collect all evidence-based immune system related viral infection as well as, provide understanding of the potential impact of Ramadan fasting on the immune system during pandemic viral infection.

\section{Discussion}

Various factors modulating the immune system, including the environmental, genetics, and nutrition, can modulate the immune system, which are briefly described below:

\section{The role of the environment in modulating immune system}

Some environmental factors can affect the functioning of the immune system, resulting in the development of DIT (developmental immunotoxicology) to assess the impact of chemical, biological, physical, or physiological factors on the development of the immune system [12]. Immune factors that modulate the immune system include exposure to chemicals, infectious diseases, and cloning of parasites and germs in the body [13]. For example, exposure of a pregnant mother to certain heavy metals that can cross the placenta can lead to problems with the baby's immune system [14,15]. The early life of everyone being is a window of opportunity and vulnerability that affects the development and evolution of the immune system [13]. The immune system is a system of flux after adaptation which is created by being in various conditions and limitations. Although the pressure of natural selection has driven the evolution of the immune system, in recent years we have also rapidly changed our environment [16]. Another example of an immune system modifier is the exposure to the fungus Aspergillus flavus, which can infect edible seeds and produces aflatoxin B1. This toxin is directly toxic to the immune system and, after being metabolized by the body's oxidation system, is converted to an active mutagenic-carcinogen with immunotoxicity that increases the chances of developing advanced cancer [17].

\section{The role of nutrition in modulating immune system}

The consumption or non-consumption of certain vitamins and nutrients is effective in the functioning of the immune system. Based on the previous studies, diet, especially from infancy, can play a crucial role in preventing allergies, especially in the first 10 years of life [18]. Dietary diversity is thought to affect allergy symptoms by influencing the microbiome and the immune system. The change in the immune system is due to a combination of antigen tolerance mechanisms such as $\mathrm{B}$ and $\mathrm{T}$ regulatory cells, immune-regulatory cytokines, and suppressed IgE antibodies [19]. Studies of dietary patterns during pregnancy also suggest that eating a Mediterranean diet may reduce eczema and wheezing in children [20]. On the other hand, vitamins such as A, B6, B12, D, C, E, and folic acid, rare elements such as zinc, iron, selenium, magnesium, and copper, play an important and supplementary role in supporting the innate and acquired immune system. The deficiencies in these elements and vitamins can lead to reduced resistance to infections [21]. Other foods that support the immune system, especially in inflammatory responses, are omega-3 fatty acids [22]. These vitamins and nutrients are needed for the development and sustainability of physical barriers, production and activity of antimicrobial proteins, growth, differentiation, and motility of intracellular cytotoxins, phagocytosis, and killing activities of neutrophils and macrophages. For example, the role of vitamin $\mathrm{C}$ is to support the function of epithelial barriers, the growth and function of innate and acquired immune cells by migrating white blood cells to the site of infection, phagocytosis, microbial killing, and antibody production. The role of vitamin D is also in many immune cells that have vitamin D receptors and affect their function after binding to ligands. For instance, they increase the differentiation of monocytes into macrophages and enhance their killing capacity, modulating the production of inflammatory cytokines, and supporting antigen delivery. Therefore, vitamin D metabolites are used to regulate the production of specific antimicrobial proteins that directly kill pathogens and may help to reduce the infection in the lungs $[23,24]$. Lack of nutrients containing essential fatty acids such as eicosapentaenoic acid (EPA), docosahexaenoic acid (DHA), and omega-3 fatty acids can lead to delays or reduced inflammation accuracy, which can be important in COVID-19 pathogenesis $[25,26]$. Zinc deficiency can also lead to impaired in the formation, activity, and maturation of lymphocyte, disruption of intracellular communication through cytokines, and impaired intrinsic defense. Its deficiency, especially in children, leads to increased diarrhea and respiratory complications $[27,28]$.

\section{The role of genetics in modulating immune system}

The immune system is very active in some people, while in others is less so. As Pastor Scientists have shown, there is a difference in how populations react to infection which leads to people prone to certain diseases, and these responses are largely controlled by genetics and natural selection plays an important role in the formation of immune profiles. They also proved that the genetic inheritance that Neanderthals (a species of extinct humans associated with the European Ice Age) passed on to Europeans affected their ability to respond to viral challenges. The range of immune responses in Africans and Europeans varies, especially for genes involved in inflammatory and antiviral responses. These differences can be largely attributed to a variety of genetic differences that modulate the expression of immune genes. The findings also show that some populations are exposed to diseases such as lupus, which is more common in Africa than in Europe. Nearly $4 \%$ of modern European genomes are of Neanderthal origin, with mutations that have been passed on to Europeans. For example, mutations that affect immune response control, such as mutations that modify gene expression in response to viral infections and this mutation gives the population the advantage of inheriting it [29]. On the other hand, other research has illustrated that genetic differences in the human immune system may affect the susceptibility or severity of infection by acute respiratory syndrome Coronavirus 2 [30]. ACE2 (angiotensin-converting enzyme-2) is a gene encoding the converting enzyme angiotensin, which is a receptor for the SARS-COV virus and the Human coronavirus NL63 (HCoV-NL63) [31,32]. The findings suggest that ACE2 gene polymorphism may be associated with higher levels of ACE2 in East Asian populations. Analysis of the single-strand RNA sequence of Asian donors shows that there is a higher rate of ACE2 expression in the Asian population than in American-African donors [33]. In contrast, the analysis of ACE2 expression using RAN sequence and microarray information of the lung tissue of the control 
group suggests that there is no significant difference between Asian and Caucasian race or male and female sex [34]. Studies have shown that the difference in the distribution of allele frequencies (AF) of eQTLS for ACE2 in different populations indicates the diversity of ACE2 expression patterns in populations and that there is a relative difference in QTLS AFs between East and South Asia. It can lead to differences in the expression of ACE2 in different populations and races in Asia [35]. On the other hand, the microbiome in the gut and other organs have vital effects on the human immune system in both health and disease. Normal flora does not have the same effects on the host the immune system in all organisms, but in some, it is more important and has significant effects [36].

\section{Fasting versus eating states and immune system}

Among many other elements affecting the immune system, a significant one is the food humans eat [37]. Eating patterns can influence in boosting of the immune system, it is vital to know the practical and scientific complications of eating patterns such as low-calorie diets during fasting [38]. The caloric restriction and fasting improve the health of overweight people and enhance their immune function [39]. Moreover, researches have shown that short-term starvation sensitizes tumors to chemotherapy and can reduce chemotherapy-associated toxic side effects, that protect normal cells, comprise stem cells, and immune cells [40]. Many studies prove that human cells have got more resistance to toxins by prolonging fasting up to 48-120 hours [41-44]. On the other hand, some studies show the role of eating healthy food to supply vigorous immunity against viral infection and decrease the risk of infection [45]. Several investigations indicate the critical role of fasting to enhances the innate immunity under the control of endocrine system by elevation of cytokine especially IL-1 $\alpha$ in healthy fasting human compared to healthy non-fasting ones $[38,46,47]$. Fasting leads to an increase in B cell immunity [48], interferon- ${ }_{\square}$ in plasma [49], and white blood cells especially neutrophil, natural killer-cell and monocyte activity [50]. The intermittent fasting shows a positive effect to reduce inflammation and enhances killing ability of macrophages against Mycobacterium tuberculosis [5]. Overall, the Ramadan and all forms of fasting could turn in the favor of immune system if practiced in healthy regiments and maintenance of balanced nutritional diets.

\section{Dehydration and immune system}

Dehydration is commonly describe a deficit of water from all fluid compartments of the body which can cause hypovolemic shock [51]. Researches have shown non-energetic resources and significantly water can directly modulate the immune system [52,53]. Ramadan fasting induce decreased extracellular electrolytes especially $\mathrm{Na}^{+}$and $\mathrm{Cl}^{-}$as a result of body fluid restriction due to the fasting [54]. Several studies demonstrate that total body dehydration depress the immune system [55,56]. In addition, severe dehydration decreases the neutrophil function and immunoglobulins such as IgA, IgG, IgM [57]. Some study demonstrates that dehydration decreases lymphocyte cells in lymphoid organs by contrast increase in destructive cells and inhibiting the process of cell mitoses [58]. Meanwhile, some other study indicate that the dehydration can enhance the innate immunity [52]. Moreover, recent study have approved development of innate immune performance during dehydration in adult reptiles [59]. Also, some evidence show that dehydration leads to increased concentration of immune proteins $[52,60]$. On the other hand, dehydration remains the causative factor of cellular shrinkage $[61,62]$. Although, some studies suggest possible positive effects of dehydration on the immune function, yet, it is important to the people who fast to avoid severe dehydration because of the higher risks that may endanger life.

\section{Ramadan fasting and risk of infection}

Most researches conducted on the out-turn of fasting took a reduced calorie intake into consideration and run down other potential facts regarding the possibility of dehydration and airways dryness [63]. As Ramadan fasting includes complete refrain from all drinks and foods for one month period, the outcomes of most researches on intermittent fasting could not be simply generalized to Ramadan fasting. Fasting from dawn to dusk causes dry mouth and dry throat that is claimed to be linked with an increase in susceptibility of catching an infection. Although, this claim remains arguable by religious and some health authorities, yet, the evidence is neither conclusive nor incontrovertible [64]. As the body's immune function is directly a depending factor on nutrient balances in the human body, it's even more salient to achieve this nutrition balanced during a pandemic that has no promising treatment [45]. Innumerable studies that conducted over the effect of Ramadan fasting on the immune function changes showed no immune function malfunctions [65]. Conversely, many studies suggest Ramadan fasting can boost the immune system's potential in fighting infections. This can be interpreted as a result of an increase in some immunoglobulins like IgA [66]. Furthermore, many complement system's elements show an elevation during fasting Ramadan, these elevations of elements such as (C4) lead to preventing the risk of infecting so many microorganisms to the people who fast [67]. Some clinical evidence proved these immunoprotective effects of fasting. In one study by Lahdimawan and collagenous, the effect of Ramadan fasting on preventing healthy individuals from tuberculosis and increasing the protection in tuberculosis patients is shown [68]. Yet, as promising as these results may look, still, there are many alarms to be aware of regarding fasting. Many other studies present some of the adverse results of fasting. In a study, Develioglu et al. suggest IgG levels were being reduced as a result of Ramadan fasting [65]. Moreover, in accordance with some studies over groups of patients with chronic diseases, fasting has various effects. Diabetic patients are at risk of developing complications from fasting, so they should not fast. Meanwhile, fasting has not shown any significant effect on diarrheal patients. Acquired immunodeficiency syndrome (AIDS) patients if fasted should receive extra care during and after fasting. Fasting doesn't affect the effectiveness of antihelminthic treatments, while for ulcer patients, it is not recommended to fast due to the higher risks of developing complications as a result [69]. As for fasting during COVID-19 pandemic, the literature is not conclusive in whether fasting Ramadan elevates the infection risk or not. Besides, as we have mentioned prior, the dry throat might increase the susceptibility of infecting a virus, yet no evidence proved this claim for COVID-19 as well [64]. Therefore, this confusion in literature led to general and specialized people to adopt their own approaches in deciding the feasibility of fasting during a pandemic. Correspondingly, people with higher risks of infection including elderly and frail need to refrain themselves from fasting to steer clear of potential livethreatening consequences.

\section{Ramadan fasting and oxidative stress}

The oxidative stress is a state in which free radicals and reactive oxygen species are in excess compared to the cells ability to detoxify their effect by anti-oxidant mechanisms [70]. Oxidative stress participates mainly in many human diseases such as hypertension, cardiovascular, cancer, pulmonary, neurological, liver, and renal diseases, besides its role in the aging process [71]. Throughout the literature, it is believed that fasting is good for health, especially it reduces the production of reactive oxygen species and free radicals [72]. However, evidence manifested a large scope of health benefits other than taking the edge 
of free-radical production [8]. In a study by Faris et al. the impact of Ramadan fasting on oxidative stress is measured through urinary $15 \mathrm{~F}_{2 \mathrm{t}}$ Isoprostane which is a compound similar to prostaglandin and used as a sensitive biomarker assessing of oxidative stress [73]. The results of the study show the impact of Ramadan fasting on oxidative stress to be linked to the body weight, after the Ramadan, participants of the study re-gained weight in a statistically significant way, as a result, the oxidative stress markers elevated in a statistically significant manner as well [73]. The outcomes of that study suggest that, practicing Ramadan or intermitted fasting does not result in reduced exposure to the oxidative stress, unless accompanied by substantial lifestyle changes and healthy eating behavior maintains a healthy body weight [73]. As COVID-19 complications become more obvious, many studies suggest that a significant etiology of the disease is the generation of oxidative stress [70]. Since elderly patient and patient with chronic lung diseases are among high-risk groups of COVID-19 [74], it's important to quantify the effect of fasting in association with a risk assessment to COVID-19. The impacts of Ramadan intermittent fasting on biomarkers for Oxidant/Antioxidant Stress to elderly male patients with stable conditions of chronic obstructive pulmonary disease (COPD) has been assessed in a study conducted by Mrad and collagenous. Two oxidative stress biomarkers (thiobarbituric acid reactive substances [TBARS, $\mu \mathrm{mol} / \mathrm{L}]$, and homocysteine $[\mu \mathrm{mol} / \mathrm{L}])$ with five antioxidant stress biomarkers (catalase [U/ml], superoxide dismutase [SOD, ng/ $\mathrm{ml}]$, zinc $[\mu \mathrm{mol} / \mathrm{L}]$, ceruloplasmin $[\mathrm{g} / \mathrm{L}]$, albumin $[\mathrm{g} / \mathrm{L}])$ measured through the course of Ramadan in three stages, before, in the end, and after Ramadan every day after iftar. However, finding observed form the study, showed no statistically significant induce of Ramadan fasting on the neither oxidative nor anti-oxidant stress biomarkers or the clinical status of COPD patients [75]. Although, Ramadan intermittent fasting proved beneficent to control an elevation of malondialdehyde (MDA) oxidative stress biomarker [76]. Yet, the result of another systematic review that included 7 studies conducted on athletics, 13 studies on nonathletic but healthy precipitants, and 10 studies on non-healthy subjects by RJ Shephard, concluded the influence of the Ramadan intermittent fasting to be of minimal influence on the oxidative/antioxidant stress biomarkers in athletes. While the benefit of fasting was more for healthy nonathletic individuals and patient groups [77]. Therefore, the beneficence of Ramadan fasting to reduce oxidative stress and improve antioxidant status is not merely related to the fasting, but controlled by many other factors including lifestyle, body weight and general health status of the fasting person.

\section{Conclusion}

So many justifiable concerns arise to the consequences of refraining the body from essential nutrients and fluids for prolonged periods of time through a day. Especially this practice might intricate the health status of selected groups including the elderly and people having chronic diseases. On the flip side, many studies suggest that intermittent fasting boost the immune response of the body towards infections. These conflicting data over the interconnection between practicing fasting and body's immune function evinces how interesting and complicated relation it is? Nourishment is the principal necessity for humans to pull through life, the immune system is majorly affected by nutrient dosage, types, and qualities. Nevertheless, many studies proved that intermittent fasting improves immune cell abilities for killing pathogens. It is well known that dehydration causes many serious health threats including immune function to depress yet, some evidence shows the innate immunity improvements as a result of dehydration. There is no conclusive evidence regarding the relationship between fasting and increasing or decreasing the risk of catching a virus or improving oxidative/antioxidant stress status as well. So, Muslims who practice fasting during pandemic face a circumstance in which no concrete scientific evidence proves the safety or danger of this religious practice.

\section{Competing interests}

The authors declare that they have no competing interests.

\section{Funding}

This research did not receive any specific grant from funding agencies in the public, commercial, or not-for-profit sectors.

\section{Authors' contributions}

$\mathrm{HB}, \mathrm{KH}, \mathrm{SQ}, \mathrm{RA}, \mathrm{MT}, \mathrm{AA}$ and MB participated in the design of the study, data collection, and drafted the manuscript. HF and AHB supervising the study and participated in draft review. All authors have read and approved the final version of the manuscript and agree with the order of presentation of the authors.

\section{Acknowledgments}

Not applicable.

\section{References}

1. Rothan HA, Byrareddy SN (2020) The epidemiology and pathogenesis of coronavirus disease (COVID-19) outbreak. Journal of Autoimmunity 26: 102433.

2. Speakman JR, Mitchell SE (2011) Caloric restriction. Molecular Aspects of Medicine 32: 159-221.

3. Thorn J (2001) Seasonal variations in exposure to microbial cell wall components among household waste collectors. The Annals of Occupational Hygiene 45: 153-156.

4. El Bilbeisi AH, El Afifi A, Farag HA, Wahedy KM, Srour M (2019) Effects of Ramadan Fasting on Anthropometric Measures. Blood Pressure and Glucose Level among Type. Journal of Nutrition and Health Sciences 6: 29-30.

5. Adawi M, Watad A, Brown S, Aazza K, Aazza H, et al. (2017) Ramadan fasting exerts immunomodulatory effects: insights from a systematic review. Frontiers in Immunology 8: 1144

6. Wardwell L, Chapman-Novakofski K, Herrel S, Woods J (2008) Nutrient intake and immune function of elderly subjects. Journal of the American Dietetic Association 108: 2005-2012

7. Hutch RA (2013) Health and healing: Spiritual, pharmaceutical, and mechanical medicine. Journal of Religion and Health 52: 955-965.

8. Longo VD, Mattson MP (2014) Fasting: molecular mechanisms and clinical applications. Cell Metabolism 19: 181-192.

9. Mirzaei B, Rahmani-Nia F, Moghadam MG, Ziyaolhagh SJ, Rezaei A (2012) The effect of ramadan fasting on biochemical and performance parameters in collegiate wrestlers. Iranian Journal of Basic Medical Sciences 15: 1215.

10. Develioglu ON, Kucur M, Ipek HD, Celebi S, Can G, et al. (2013) Effects of Ramadan fasting on serum immunoglobulin $\mathrm{G}$ and $\mathrm{M}$, and salivary immunoglobulin $\mathrm{A}$ concentrations. Journal of International Medical Research 41: 463-472.

11. Kacimi S, Refat A, Fararjeh MA, Bustanji YK, Mohammad MK, et al. (2012) Intermittent fasting during Ramadan attenuates proinflammatory cytokines and immune cells in healthy subjects. Nutrition Research 32: 947-955.

12. Duramad P, Tager IB, Holland NT (2007) Cytokines and other immunological biomarkers in children's environmental health studies. Toxicology Letters 172: 48-59.

13. MacGillivray DM, Kollmann TR (2014) The role of environmental factors in modulating immune responses in early life. Frontiers in Immunology 5: 434.

14. Gundacker C, Hengstschläger M (2012) The role of the placenta in fetal exposure to heavy metals. Wiener Medizinische Wochenschrift 162: 201-206.

15. Mudd SH, Brosnan JT, Brosnan ME, Jacobs RL, Stabler SP, et al. (2007) Methyl balance and transmethylation fluxes in humans. The American Journal of Clinical Nutrition 85: 19-25. 
16. Di Cerbo A, Palmieri B, Aponte M, Morales-Medina JC, Iannitti T (2016) Mechanisms and therapeutic effectiveness of lactobacilli. Journal of Clinical Pathology 69: 187-203.

17. Dietert RR, Golemboski KA, Austic RE (1994) Environment-immune interactions. Poultry Science 73: 1062-1076.

18. Venter C, Maslin K, Holloway JW, Silveira LJ, Fleischer DM, et al. (2020) Different measures of diet diversity during infancy and the association with childhood food allergy in a UK birth cohort study. The Journal of Allergy and Clinical Immunology: In Practice.

19. Venter C, Greenhawt M, Meyer RW, Agostoni C, Reese I, et al. (2020) EAACI position paper on diet diversity in pregnancy, infancy and childhood: Novel concepts and implications for studies in allergy and asthma. Allergy 75: 497-523.

20. Venter C, Eyerich S, Sarin T, Klatt KC (2020) Nutrition and the immune system: A complicated tango. Nutrients 12: 818 .

21. Gombart AF, Pierre A, Maggini S (2020) A review of micronutrients and the immune System-Working in harmony to reduce the risk of infection. Nutrient 12: 236

22. Calder PC (2013) Omega-3 polyunsaturated fatty acids and inflammatory processes: nutrition or pharmacology? British Journal of Clinical Pharmacology 75: 645-662.

23. Greiller CL, Martineau AR (2015) Modulation of the immune response to respiratory viruses by vitamin D. Nutrients 7: 4240-4270.

24. Gombart AF (2009) The vitamin D-antimicrobial peptide pathway and its role in protection against infection. Future Microbiology 4: 1151-65.

25. Mehta P, McAuley DF, Brown M, Sanchez E, Tattersall RS, et al. (2020) COVID-19: consider cytokine storm syndromes and immunosuppression. Lancet (London, England) 395: 1033 .

26. Pedersen SF, Ho YC (2020) SARS-CoV-2: a storm is raging. The Journal of Clinical Investigation 130 .

27. Gammoh NZ, Rink L (2017) Zinc in infection and inflammation. Nutrients 9: 624.

28. Maares M, Haase H (2016) Zinc and immunity: An essential interrelation. Archives of Biochemistry and Biophysics 611: 58-65.

29. Quach H, Rotival M, Pothlichet J, Loh YH, Dannemann M, et al. (2016) Genetic adaptation and Neandertal admixture shaped the immune system of human populations. Cell 167: 643-656.

30. Nguyen A, David JK, Maden SK, Wood MA, Weeder BR, et al. (2020) Human leukocyte antigen susceptibility map for SARS-CoV-2. Journal of Virology, Apr 17.

31. Zhou P, YANG X, wANG XG, HU B. ZHANG w. Si Hr, zHu y, et al. (2020) A pneumonia outbreak associated with a new coronavirus of probable bat origin. Nature 579: $270-273$.

32. Lu R, Zhao X, Li J, Niu P, Yang B, et al. (2020) Genomic characterisation and epidemiology of 2019 novel coronavirus: implications for virus origins and receptor binding. The Lancet 395: 565-574.

33. Zhao Y, Zhao Z, Wang Y, Zhou Y, Ma Y, et al. (2019) Single-cell RNA expression profiling of ACE2, the putative receptor of Wuhan 2019-nCov. BioRxiv.

34. Cai G (2019) Bulk and single-cell transcriptomics identify tobacco-use disparity in lung gene expression of ACE2, the receptor of 2019-nCov. MedRxiv.

35. Cao Y, Li L, Feng Z, Wan S, Huang P, et al. (2020) Comparative genetic analysis of the novel coronavirus (2019-nCoV/SARS-CoV-2) receptor ACE2 in different populations. Cell Discovery 6: 1-4.

36. Salek Farrokhi A, Darabi N, Yousefi B, Askandar RH, Shariati M, et al. (2019) Is it true that gut microbiota is considered as panacea in cancer therapy? Journal of Cellular Physiology 234: 14941-1450.

37. Kau AL, Ahern PP, Griffin NW, Goodman AL, Gordon JI (2011) Human nutrition, the gut microbiome and the immune system. Nature 474: 327-336.

38. Mahmood MM, Mohammed KI (2010) Effect of Ramadan fasting on the levels of IL$1 \alpha$, IL-2, IL-6 and IL-8 cytokines. Diyala Journal For Pure Science 6: 308-313.

39. Mattson MP, Wan R (2005) Beneficial effects of intermittent fasting and caloric restriction on the cardiovascular and cerebrovascular systems. The Journal of Nutritional Biochemistry 16: 129-137.

40. Di Biase S, Lee C, Brandhorst S, Manes B, Buono R, et al. (2016) Fasting-mimicking diet reduces HO-1 to promote T cell-mediated tumor cytotoxicity. Cancer Cell 30: 136146.
41. Guevara-Aguirre J, Balasubramanian P, Guevara-Aguirre M, Wei M, Madia F, et al. (2011) Growth hormone receptor deficiency is associated with a major reduction in pro-aging signaling, cancer, and diabetes in humans. Science Translational Medicine 3: 70 ra13.

42. Lee C, Longo VD (2011) Fasting vs dietary restriction in cellular protection and cancer treatment: from model organisms to patients. Oncogene 30: 3305-3316.

43. Fontana L, Partridge L, Longo VD (2010) Extending healthy life span-from yeast to humans. Science 328: 321-326.

44. Cheng CW, Adams GB, Perin L, Wei M, Zhou X, et al. (2014) Prolonged fasting reduces IGF-1/PKA to promote hematopoietic-stem-cell-based regeneration and reverse immunosuppression. Cell Stem Cell 14: 810-823.

45. Farag HA, Baqi HR, Hussein YT, Shareef OH, Qadir SA, et al. (2020) The Role of Nutrients in Supporting The Immune System Against Viral Infection; Newly Emerged Coronavirus (COVID-19): A Narrative Review. Kurdistan Journal of Applied Research 27: 84-96.

46. Mastorakos GE, Chrousos GP, Weber JS (1993) Recombinant interleukin-6 activates the hypothalamic-pituitary-adrenal axis in humans. The Journal of Clinical Endocrinology \& Metabolism 77: 1690-1694

47. Bateman A, Singh A, Kral T, Solomon S (1989) The immune-hypothalamic-pituitaryadrenal axis. Endocrine Reviews 10: 92-112.

48. Trollmo C, Verdrengh M, Tarkowski A (1997) Fasting enhances mucosal antigen specific B cell responses in rheumatoid arthritis. Annals of the Rheumatic Diseases 56: $130-134$.

49. Hiramoto K, Homma T, Jikumaru M, Miyashita H, Sato EF, et al. (2008) Fasting differentially modulates the immunological system: its mechanism and sex difference. Journal of Clinical Biochemistry and Nutrition 43: 75-81.

50. Uden AM, Trang L, Venizelos N, Palmblad J (1983) Neutrophil functions and clinical performance after total fasting in patients with rheumatoid arthritis. Annals of the Rheumatic Diseases 42: 45-51.

51. Sarhill N, Walsh D, Nelson K, Davis M (2001) Evaluation and treatment of cancerrelated fluid deficits: volume depletion and dehydration. Supportive Care in Cancer 9: 408-419.

52. Brusch GA, DeNardo DF (2017) When less means more: dehydration improves innate immunity in rattlesnakes. Journal of Experimental Biology 220: 2287-2295.

53. Viney ME, Riley EM, Buchanan KL (2005) Optimal immune responses: immunocompetence revisited. Trends in Ecology \& Evolution 20: 665-669.

54. Horne BD, May HT, Anderson JL, Kfoury AG, Bailey BM (2008) Usefulness of routine periodic fasting to lower risk of coronary artery disease in patients undergoing coronary angiography. The American Journal of Cardiology 102: 814-819.

55. Greenleaf JE, Jackson CG, Lawless DE (1995) CD4+/CD8+ T-lymphocyte ratio: effects of rehydration before exercise in dehydrated men. Medicine and Science in Sports and Exercise 27: 194-199.

56. DeGiorgi L, Altomare D (1992) Modification of the immune system following mental and physical stress. Bulletin de l'Institut Pasteur 90: 99-107.

57. Chishaki T, Umeda T, Takahashi I, Matsuzaka M, Iwane K, et al. (2013) Effects of dehydration on immune functions after a judo practice session. Luminescence 28: 114 120

58. Guseinov TS, Guseinova ST (2008) Effect of dehydration on morphogenesis of the lymphatic network and immune structures in the small intestine. Bulletin of Experimental Biology and Medicine 145: 755-757.

59. Brusch IV GA, DeNardo DF (2019) Egg desiccation leads to dehydration and enhanced innate immunity in python embryos. Developmental \& Comparative Immunology 90: $147-151$

60. Fortes MB, Diment BC, Di Felice U, Walsh NP (2012) Dehydration decreases saliva antimicrobial proteins important for mucosal immunity. Applied Physiology, Nutrition, and Metabolism 37: 850-859.

61. Hillman AR, Vince RV, Taylor L, McNaughton L, Mitchell N, et al. (2011) Exerciseinduced dehydration with and without environmental heat stress results in increased oxidative stress. Applied Physiology, Nutrition, and Metabolism 36: 698-706.

62. Schliess F, Häussinger D (2002) The cellular hydration state: a critical determinant for cell death and survival. Biological Chemistry 383: 577-583.

63. Tootee A, Larijani B (2020) Ramadan fasting during Covid-19 pandemic. Journal of Diabetes and Metabolic Disorders. 
64. Zijoud SR, Farahani AJ (2020) Ramadan coincides with the Covid-19 pandemic: What should be done? Disaster Medicine and Public Health Preparedness.

65. Develioglu ON, Kucur M, Ipek HD, Celebi S, Can G, et al. (2013) Effects of Ramadan fasting on serum immunoglobulin $\mathrm{G}$ and $\mathrm{M}$, and salivary immunoglobulin A concentrations. Journal of International Medical Research 41: 463-472.

66. Khazaei HA, Bokaeian M, Jalili A (2014) The effect of fasting on the immune system of athletes during holly Ramadan. Zahedan Journal of Research in Medical Sciences 16: 44-46.

67. Heydarpour A, Darabi S, Zamanian H, Ahmari Tehran H, Mesdaghi M (2015) The effect of Ramadan fasting on blood biochemical factors related to immune system in summer. Qom University of Medical Sciences Journal 9: 50-56.

68. Lahdimawan A, Handono K, Indra MR, Prawiro SR (2014) Effect of Ramadan fasting on the ability of serum, PBMC and macrophages from healthy subjects to kill M. tuberculosis. IOSR Journal of Pharmacy and Biological Sciences 9: 24-29.

69. Bragazzi NL, Briki W, Khabbache H, Rammouz I, Mnadla S, et al. (2015) Ramadan fasting and infectious diseases: a systematic review. The Journal of Infection in Developing Countries 9: 1186-1194.

70. Baqi HR, Farag HA, El Bilbeisi AH, Askandar RH, El Afifi AM (2020) Oxidative Stress and Its Association with COVID-19: A Narrative Review. Kurdistan Journal of Applied Research.
71. Montuschi P, Barnes PJ, Roberts LJ (2004) Isoprostanes: markers and mediators of oxidative stress. The FASEB journal 18: 1791-1800.

72. Zenz G, Jačan A, Reichmann F, Farzi A, Holzer P (2019) Intermittent fasting exacerbates the acute immune and behavioral sickness response to the viral mimic poly (I: C) in mice. Frontiers in Neuroscience 13: 359.

73. Faris ME, Hussein RN, Al-Kurd RA, Al-Fararjeh MA, Bustanji YK, et al. (2012) Impact of Ramadan intermittent fasting on oxidative stress measured by urinary 15--isoprostane. Journal of Nutrition and Metabolism.

74. Buzby JC (2002) Older adults at risk of complications from microbial foodborne illness. Food Review-Washington DC 25: 30-35.

75. Mrad S, Rejeb H, Ben Abdallah J, Graiet H, Ben Khelifa M, et al. (2019) The impacts of ramadan intermittent fasting on oxidant/antioxidant stress biomarkers of stable chronic obstructive pulmonary disease male patients. American Journal of Men's Health 13: 1557988319848281

76. Rothan HA, Byrareddy SN (2020) The epidemiology and pathogenesis of coronavirus disease (COVID-19) outbreak. Journal of Autoimmunity.

77. Shephard RJ (2017) Oxidative stress and Ramadan observance; a possible influence of associated dieting. Journal of Nutrition, Fasting and Health 5: 63-73.

Copyright: $\bigcirc 2020$ Farag HAM. This is an open-access article distributed under the terms of the Creative Commons Attribution License, which permits unrestricted use, distribution, and reproduction in any medium, provided the original author and source are credited. 